\title{
Resistance to extinction of an escape response as a function of the number of reinforcements'
}

\author{
R. CHRIS MARTIN \\ UNIVERSITY OF KENTUCKY
}

Support for the assumption that response strength is related to number of reinforcements in a negatively accelerated monotonic fashion has been obtained from instrumental appetitive and classical aversive conditioning situations. The relationship is investigated in an instrumental aversive (escape) situation and the results support the assumption.

The evidence generally cited as support for Hull's (1943) assumption that habit strength $\left(\mathrm{S}^{\mathrm{H}} \mathrm{R}\right)$ is related to the number of reinforcements in a negatively accelerated monotonic fashion comes from the studies of Perin (1938) and Williams (1942). Their data were obtained in an appetitively motivated instrumental conditioning situation. Evidence from aversively motivated classical conditioning situations has also tended to support Hull's assumption (Kimble \& Dufort, 1956; Prokasy, 1958; Spence \& Rutledge, 1964)。 ${ }^{2}$ In the present study resistance to extinction as a function of the number of reinforcements was investigated in an instrumental aversive situation.

Method

Subjects. The Ss were 60 naive, male hooded rats of the Long-Evans strain, ranging in age from 100 to 140 days at the beginning of the experiment. During the experimental period they were housed in individual cages with Purina lab chow and water available ad lib.

Apparatus. The main apparatus consisted of a start box, straight runway, and a goal box. The start box and alley were painted light gray and the goal box was painted flat black. A $60-\mathrm{w}$ light bulb was located 6 in. above the center of the start box. The start box was divided into upper and lower compartments by a trapdoor floor located $4-1 / 2$ in. from the top of the box. The $S$ could be placed into the upper compartment through a door at one end, and dropped onto the grid floor by releasing the trap door.

The straight runway was $4 \mathrm{ft}$. long. Its floor was composed of stainless steel rods $1 / 2$ in. from center to center. This grid extended into the startbox. Vertical photocells and associated electronic equiprient were used to measure start time (the time between the moment $S$ landed upon the grid until he left the start box), alley time (time required to traverse the runway), and total time (starting time plus alley time).

The lamp above the start box served as a CS. A motor-driven circuit breaker in series with the lamp provided two $.25 \mathrm{sec}$. "on" and "off" periods per second. The interval between the onset of the CS and drop of $S$ onto the grid was approximately $6 \mathrm{sec}$. Cessation of the CS was controlled by a photocell circuit.
Procedure. Prior to training, each S was handled a few minutes daily for three days and randomly assigned to one of four groups. The groups differed according to the number of escape training trials $(4,8,16$, or 32$)$ received before extinction. Either $1,2,4$, or 8 trials were administered per day for 4 days with an intertrial interval of $4 \mathrm{~min}$. Start time, alley time, and total time were recorded on each trial. The procedure for a given trial was as follows: $3 \mathrm{sec}$. after $S$ was placed into the top compartment of the start box, the goal box guillotine door was raised which started an electronic timer. Three sec. later the CS was turned on and $6 \mathrm{sec}$. after that $S$ was dropped onto the grid. During the last $3 \mathrm{sec}$. of the $6 \mathrm{sec}$. CS duration, S received auditory and vibratory cues from the trap-door release mechanism. The CS continued until the rat entered the goal box. The $S$ remained in the goal box $15-20 \mathrm{sec}$. while time measures were recorded. The 60- volt shock was obtained from the output of a variable-voltage autotransformer and was administered through a series resistor of $10,000 \mathrm{ohms}$.

After training, Ss received extinction trials at the rate of 10 trials per day, with the same intertrial interval, for the next 6 days. The extinction criterion was failure to reach the goal box within $60 \mathrm{sec}$. on any one trial.

Resulis

Acquisition. Performance of the four groups during acquisition is shown in Fig. 1. The points representing alley speed were obtained from medians of blocks of four trials. Although initial increases in speed were

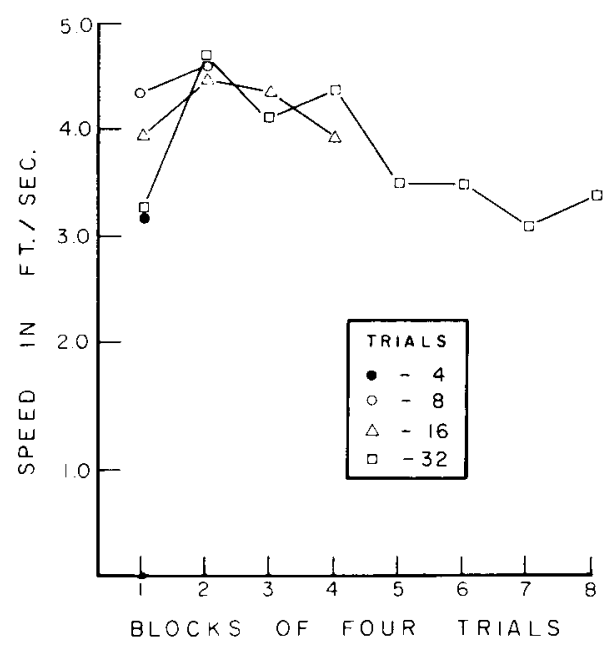

Fig. 1. Median speed in ft. per sec. during acquisition over blocks of four trials. 


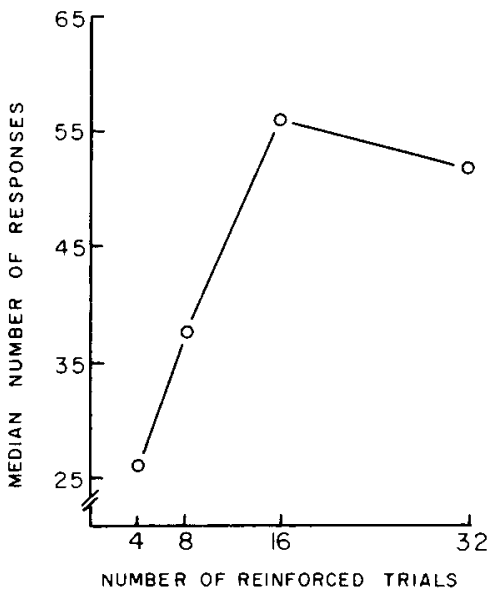

Fig. 2. Median number of responses to extinction for each group over six days of extinction, 10 trials per day.

shown by the 8,16 , and 32 trial groups, the 16 and 32 trial groups showed decrements in speed over the last few blocks of trials. An analysis of variance revealed no statistically significant differences across trials.

Extinction. The median number of responses to extinction for each group is shown in Fig. 2. The figure clearly shows that greater numbers of responses were required for extinction after greater numbers of training trials, except for the 32 trial group. An overall chisquare analysis of these median scores revealed that the groups differed at the .01 level $\left(X^{2}=14.15\right.$, df $\left.=3\right)$. A t-test between the 16 and 32 trial groups revealed no significant difference between them.

The mean starting speeds during extinction for the four groups over trials are presented in Fig. 3. Although the

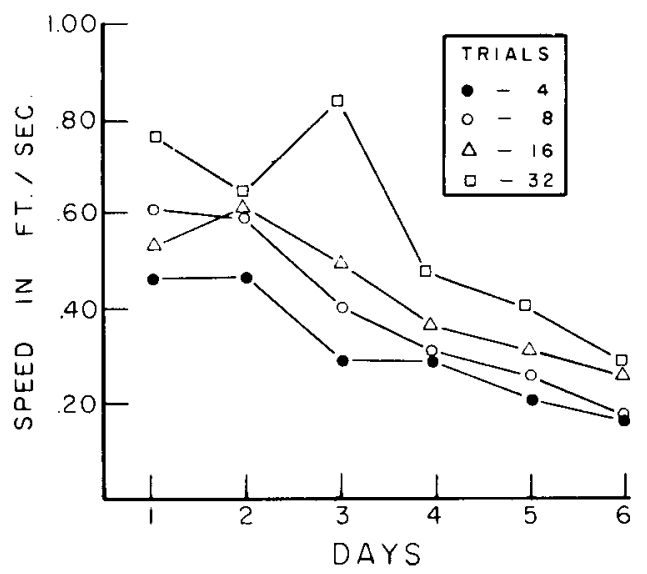

Fig. 3. Mean starting speed during extinction over six days of extinction, 10 trials per day. groups receiving greater numbers of trials were faster at almost every point, analysis of variance failed to reveal significant differences for this measure. The mean alley speed and mean total speed scores did not show any rank order differences between the groups during extinction. The alley speed scores of the 4 trial group were clearly below other groups and showed rapid extinction, but the other groups showed frequent inversions across trials.

\section{Discussion}

The results provide some support for the assumption regarding the growth of response potential with increasing numbers of reinforcements. The number of responses to extinction measure provided the most support, followed by the start speed data. The other speed measures were equivocal. The results also indicate that asymptotic resistance to extinction (when trained with the given voltage levels and intertrial interval) is reached between 16 and 32 trials.

Thus, a similar relationship between resistance to extinction and number of reinforcements has been shown to occur in both classical and instrumental as well as appetitive and aversively motivated situations. Whether a similar over-training phenomenon is found in an instrumental aversive situation, as has been shown in the instrumental appetitive situations, remains to be seen.

\section{References}

Hill, W. F., \& Spear, N. E. Extinction in a runway as a function of acquisition level and reinforcement percentage. J. exp. Psychol., $1963,65,495-500$.

Hull, C. L. Principles of behavior. New York: Appleton-CenturyCrofts, 1943.

Ison, J. R., \& Cook, P. E. Extinction performance as a function of incentive magnitude and number of acquisition trials. Psychon. Sci., 1964, 1, 245-246.

Kimble, G. A., \& Dufort, R. H. The associative factor in eyelid conditioning. J. exp. Psychol., 1956, 52, 386-391.

North, A. J., \& Stimmel, D. T. Extinction of an instrumental response following a large number of reinforcements. Psychol. Rep., 1960, 6, 227-234.

Perin, C. T. Behavior potentiality as a joint function of the amount of training and the degree of hunger at the time of extinction. J. exp. Psychol., 1942, 30, 93.113.

Prokasy, W. F. Extinction and spontaneous recovery of conditioned eyelid responses as a function of amount of acquisition and extinction training. J. exp. Psychol, 1958, 56, 319-323.

Spence, K. W., \& Rutledge, E. F. The effect of overlearning on rate of extinction of the eyelid CR. Psychon. Sci., 1964, 1, 315316.

Williams, S. B. Resistance to extinction as a function of the number of reinforcements. J. exp. Psychol., 1938, 23, 506-521.

\section{Notes}

1. This study was supported by $\mathrm{NIH}$ grant M-4952, Judson S. Brown, principal investigator. Submitted in partial fulfillment of MA degree at the University of Florida. The author gratefully acknowledges the guidance of Dr. Brown in this study.

2. A number of experimenters have reported a non-monotonic relationship after large numbers of reinforcements (Hill \& Spear, 1963; Ison \& Cook, 1964; North \& Stimmel, 1960), however, the negatively accelerated relationship was still found and aversively motivated studies have not shown such an "overtraining" effect. 